\title{
Genome evolution during bread wheat formation unveiled by the distribution dynamics of SSR sequences on chromosomes using FISH
}

Yingxin Zhang ${ }^{1,2}$, Chengming Fan ${ }^{1 *}$, Yuhong Chen ${ }^{1}$, Richard R.-C. Wang ${ }^{3}$, Xiangqi Zhang ${ }^{1}$, Fangpu Han ${ }^{1}$ and Zanmin $\mathrm{Hu}^{1,4^{*}}$

\begin{abstract}
Background: During the bread wheat speciation by polyploidization, a series of genome rearrangement and sequence recombination occurred. Simple sequence repeat (SSR) sequences, predominately located in heterochromatic regions of chromosomes, are the effective marker for tracing the genomic DNA sequence variations. However, to date the distribution dynamics of SSRs on chromosomes of bread wheat and its donors, including diploid and tetraploid Triticum urartu, Aegilops speltoides, Aegilops tauschii, Triticum turgidum ssp. dicocoides, reflecting the genome evolution events during bread wheat formation had not been comprehensively investigated.

Results: The genome evolution was studied by comprehensively comparing the distribution patterns of (AAC) ${ }_{n}$, $(\mathrm{AAG})_{n},(\mathrm{AGC})_{n}$ and $(\mathrm{AG})_{n}$ in bread wheat Triticum aestivum var. Chinese Spring and its progenitors T. urartu, A. speltoides, Ae. tauschii, wild tetroploid emmer wheat $T$. dicocoides, and cultivated emmer wheat $T$. dicoccum. Results indicated that there are specific distribution patterns in different chromosomes from different species for each SSRs. They provided efficient visible markers for identification of some individual chromosomes and SSR sequence evolution tracing from the diploid progenitors to hexaploid wheat. During wheat speciation, the SSR sequence expansion occurred predominately in the centromeric and pericentromeric regions of B genome chromosomes accompanied by little expansion and elimination on other chromosomes. This result indicated that the $\mathrm{B}$ genome might be more sensitive to the "genome shock" and more changeable during wheat polyplodization.

Conclusions: During the bread wheat evolution, SSRs including $(A A C)_{n},(A A G)_{n},(A G C)_{n}$ and $(A G)_{n}$ in $B$ genome displayed the greatest changes (sequence expansion) especially in centromeric and pericentromeric regions during the polyploidization from Ae. speltoides S genome, the most likely donor of B genome. This work would enable a better understanding of the wheat genome formation and evolution and reinforce the viewpoint that B genome was originated from $\mathrm{S}$ genome.
\end{abstract}

Keywords: Bread wheat, Polyploidization, Simple sequence repeat, FISH

\footnotetext{
*Correspondence: cmfan@genetics.ac.cn; zmhu@genetics.ac.cn

'State Key Laboratory of Plant Cell and Chromosome Engineering, Institute

of Genetics and Developmental Biology, Innovation Academy for Seed

Design, Chinese Academy of Sciences, Beijing 100101, China

Full list of author information is available at the end of the article
}

C C The Author(s). 2021 Open Access This article is licensed under a Creative Commons Attribution 4.0 International License, which permits use, sharing, adaptation, distribution and reproduction in any medium or format, as long as you give appropriate credit to the original author(s) and the source, provide a link to the Creative Commons licence, and indicate if changes were made. The images or other third party material in this article are included in the article's Creative Commons licence, unless indicated otherwise in a credit line to the material. If material is not included in the article's Creative Commons licence and your intended use is not permitted by statutory regulation or exceeds the permitted use, you will need to obtain permission directly from the copyright holder. To view a copy of this licence, visit http://creativecommons.org/licenses/by/4.0/ The Creative Commons Public Domain Dedication waiver (http://creativecommons.org/publicdomain/zero/1.0/) applies to the data made available in this article, unless otherwise stated in a credit line to the data. 


\section{Background}

Polyploidization happens widely in angiosperms, and it has been estimated that more than $70 \%$ of flowering plants have experienced polyploidization in their evolutionary history [1]. Upon merging two or more different genomes into one nucleus, the nascent polyploid faces several challenges such as rescheduling chromosome pairing, gene expression and DNA replication, and reducing the cost of large genomes. To meet these challenges, the polyploid genome must undergo a series of genetic and epigenetic changes [2-7]. The epigenetic changes are mainly associated with methylation changes, while the genetic changes mainly involve a large number of sequence removal, genome rearrangements, rewiring of gene expression, and chromosome instability [4, 7-9]. All these events occurred immediately after polyploid formation, or on an evolutionary scale $[7,8,10]$. The polyploidization events might lead to the harmonious behaviour and activity of the different constituent genomes, and facilitated the establishment of the newly formed polyploids as successful species $[1,2,6$, 11]. Hence, polyploidization is an important source of stress that facilitates rapid genome evolution.

Bread wheat ( $T$. aestivum L., $2 \mathrm{n}=6 \mathrm{x}=42$, AABBDD) is a widely cultivated cereal crop composed of three distinct subgenomes and is believed to be a product of two large rounds of hybrid speciation (homoploid and polyploidy) [12, 13]. The first round of hybridization occurred between $T$. urartu $\left(2 \mathrm{n}=2 \mathrm{x}=14, \mathrm{~A}^{\mathrm{u}} \mathrm{A}^{\mathrm{u}}\right)$ and $A e$. speltoides (a closely related source of the $\mathrm{B}$ genome, $2 \mathrm{n}=2 \mathrm{x}=14, \mathrm{SS}$ ) at approximately $0.5-0.36$ million years ago, which formed the wild emmer wheat $T$. turgidum ssp. dicocoides $\left(2 \mathrm{n}=4 \mathrm{x}=28, \quad \mathrm{~A}^{\mathrm{u}} \mathrm{A}^{\mathrm{u}} \mathrm{BB}\right)$. The second hybridization happened between the domesticated emmer wheat $T$. dicoccum $\left(2 \mathrm{n}=4 \mathrm{x}=28, \mathrm{~A}^{\mathrm{u}} \mathrm{A}^{\mathrm{u}} \mathrm{BB}\right)$ and Ae. tauschii $(2 \mathrm{n}=2 \mathrm{x}=14$, DD) at about 8000 years ago, which resulted in the emergence of the hexaploid bread wheat [13]. Following allopolyploidization of wheat, massive genomic rearrangements happened in response to this "genome shock", which played an important role in wheat speciation and domestication [11]. These genomic changes were mainly involved in non-coding sequences, such as transposable elements and simple repetitive DNA sequences, which always underwent more extensive changes than low-copy sequences and coding sequences $[4,10]$. However, how these genomic changes promoted wheat genome evolution still needs to be investigated. Moreover, as the $\mathrm{B}$ genome of wheat was more enriched in constitutive heterochromatic regions and more changeable [14-16], it was difficult to unequivocally identify the diploid donor species of $\mathrm{B}$ genome. Although extensive researches pointed that Ae. speltoides is likely the direct donor of all B genome chromosomes of wheat [16-18], more evidence is still needed.
Simple-sequence repeats (SSRs) belong to one class of repetitive sequences that are widely distributed throughout the wheat genomes, and some of them exist as large tandem arrays in the genome and can be localized on chromosomes using fluorescence in situ hybridization (FISH) [19-23]. Therefore, several SSRs have been widely used as cytological markers for chromosome identification and karyotype analysis. Their distribution patterns suggest that SSRs are mainly located in heterochromatic regions, especially the centromeric, pericentromeric and telomeric regions [21, 24, 25]. These regions could protect the repetitive sequences from the selective pressures, thus making it possible that satellite repeats could undergo significant modification during evolution, and may generate changes in their chromosomal location between closely related species, or different individuals [24], even among different generations of the same species. Thus, SSR sequences are the useful markers for tracing the genomic DNA sequence variations of chromosomal heterochromatic regions. Although the distribution of some SSRs on chromosomes was investigated in bread wheat and/or its progenitors [21, 23, 25-31], the distribution dynamics of SSRs on the chromosomes of bread wheat and its donors was not fully exploited due to the high polymorphism of SSR sequences and lack of comprehensive comparison of SSR distribution on chromosomes of bread wheat and its donors.

The main objective of this work was to analyze the distribution patterns of SSRs on chromosomes by FISH in wheat and its progenitors for tracing the possible genome changes during the process of wheat formation, especially changes that happened in the centromeric and pericentromeric regions. Investigating the genome evolution of bread wheat in the context of SSR distribution dynamics would enable us to have a better understanding of wheat genome origins and evolution.

\section{Results}

Screening of FISH positive SSR probes in bread wheat

After analysis with Tandem Repeats Finder version 4.09 [32], 21 SSR motifs (Table 1) repeated more than 5 times in the wheat genome were labelled and used for FISH positive SSR probes screening. After hybridization with mitotic chromosomes of bread wheat using SSR sequences as the probes for FISH, a total of $6 \mathrm{SSR}$ sequences, $(\mathrm{AAC})_{\mathrm{n}},(\mathrm{AAG})_{\mathrm{n}},(\mathrm{ACA})_{\mathrm{n}},(\mathrm{AG})_{\mathrm{n}},(\mathrm{AGC})_{\mathrm{n}}$ and $(\mathrm{ACG})_{\mathrm{n}}$, displayed strong and stable FISH signals and 3 SSR sequences, $(\mathrm{AGG})_{\mathrm{n}},(\mathrm{ATC})_{\mathrm{n}}$ and $(\mathrm{ACC})_{\mathrm{n}}$ showed weak FISH signals on chromosomes of bread wheat (Figs. 1, 2 and 3). Among these 9 FISH positive SSR sequences, $(\mathrm{ACA})_{\mathrm{n}}$ and $(\mathrm{AAC})_{\mathrm{n}}$ showed similar signal distribution (Fig. 3a and b), and $(A G C)_{n}$ and $(A C G)_{n}$ showed similar signal distribution (Fig. $3 \mathrm{c}$ and d). 
Table 1 SSR primers for probe labeling

\begin{tabular}{|c|c|c|c|}
\hline \multirow{2}{*}{$\begin{array}{l}\text { SSR } \\
\text { motifs }\end{array}$} & \multicolumn{2}{|l|}{ Primers for probe labelling } & \multirow{2}{*}{$\begin{array}{l}\text { FISH signals } \\
\text { on wheat } \\
\text { chromosome }\end{array}$} \\
\hline & Forward primer $\left(5^{\prime}-' 3\right)$ & Reverse primer (5'-'3) & \\
\hline AAC & AACAACAACAACAACAACAACAACAACAAC & GTTGTTGTTTTGTTGTGTTGTTGTGTT & Strong \\
\hline AAG & AAGAAGAAGAAGAAGAAGAAGAAGAAGAAG & 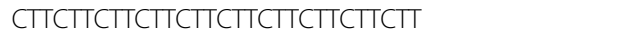 & Strong \\
\hline AGC & AGCAGCAGCAGCAGCAGCAGCAGCAGCAGC & GCTGCTGCTGCTGCTGCTGCTGCTGCTGCT & Strong \\
\hline ACG & ACGACGACGACGACGACGACGACGACGACG & CGTCGTCGTCGTCGTCGTCGTCGTCGTCGT & Strong \\
\hline ACA & ACAACAACAACAACAACAACAACAACAACA & TGTTGTTGTTGTTGTTGTTGTTGTTGTGT & Strong \\
\hline$A G$ & AGAGAGAGAGAGAGAGAGAG & СТСТСТСТСТСТСТСТСТСТ & Strong \\
\hline AGG & AGGAGGAGGAGGAGGAGGAGGAGGAGGAGG & ССТССТССТССТССТССТССТССТССТССТ & Weak \\
\hline ATC & ATCATCATCATCATCATCATCATCATCATC & GATGATGATGATGATGATGATGATGATGAT & Weak \\
\hline ACC & ACCACCACCACCACCACCACCACCACCACC & GGTGGTGGTGGTGGTGGTGGTGGTGGTGGT & Weak \\
\hline GT & GTGTGTGTGTGTGTGTGTGT & ACACACACACACACACACAC & None \\
\hline TA & TATATATATATATATATATA & TATATATATATATATATATA & None \\
\hline GC & GCGCGCGCGCGCGCGCGCGC & GCGCGCGCGCGCGCGCGCGC & None \\
\hline CGG & CGGCGGCGGCGGCGGCGGCGGCGGCGGCGG & CCGCCGCCGCCGCCGCCGCCGCCGCCGCCG & None \\
\hline GTC & GTCGTCGTCGTCGTCGTCGTCGTCGTCGTC & GACGACGACGACGACGACGACGACGACGAC & None \\
\hline GGA & GGAGGAGGAGGAGGAGGAGGAGGAGGAGGA & ССТССТССТССТССТССТССТССТССТССТ & None \\
\hline TCC & 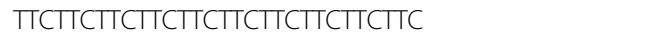 & GAAGAAGAAGAAGAAGAAGAAGAAGAAGAA & None \\
\hline GCG & GCGGCGGCGGCGGCGGCGGCGGCGGCGGCG & CGCCGCCGCCGCCGCCGCCGCCGCCGCCGC & None \\
\hline TCA & TCATCATCATCATCATCATCATCATCATCA & TGATGATGATGATGATGATGATGATGATGA & None \\
\hline GAG & GAGGAGGAGGAGGAGGAGGAGGAGGAGGAG & СТССТССТССТССТССТССТССТССТССТС & None \\
\hline GCAC & GCACGCACGCACGCACGCACGCACGCACGCACGCACGCAC & GTGCGTGCGTCGTGCGTGCGTGCGTGCGTGCGTGCGTGC & None \\
\hline TAAT & TAATTAATTAATTAATTAATTAATTAATTAATTAATTAAT & ATTAATTAATTAATTAATTAATTAATTAATTAATTAATTA & None \\
\hline
\end{tabular}

$(A A C)_{n},(A A G)_{n},(A G C)_{n}$ and $(A G)_{n}$ were selected for extensive investigation.

The distribution patterns of $(A A C)_{n}$ on chromosomes of bread wheat and its progenitors

In Chinese Spring, $(\mathrm{AAC})_{\mathrm{n}}$ displayed a strong clustered hybridization pattern on all chromosomes of the $\mathrm{B}$ genome, and some of the adjacent signals tended to be coalesced and appeared as a condensed large band (Fig. 4f and j). Sporadically weak signals were detected on chromosomes 2A, 4A and 7A (Fig. 4f and n). No obvious signals were observed on $\mathrm{D}$ genome chromosomes (Fig. 4f). In T. urartu, the (AAC) $\mathrm{n}$ motif produced several strong spot-like signals in the pericentromeric regions of both arms of chromosome $1 \mathrm{~A}$, the centromeric region of chromosome $4 \mathrm{~A}$, a signal on proximal third
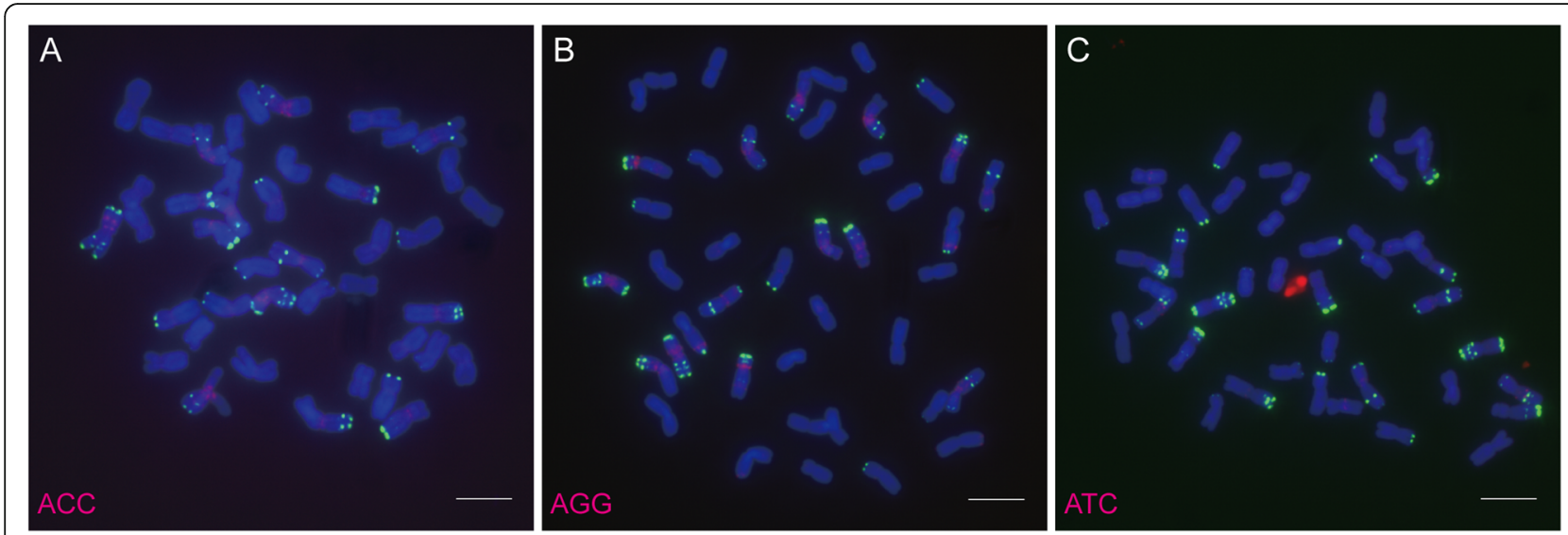

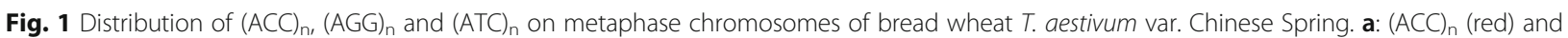
pSc119.2 (green); b: (AGG) $($ red) and pSc119.2 (green); c: (ATC) (red) and pSc119.2 (green). Bar $=10 \mu \mathrm{m}$ 

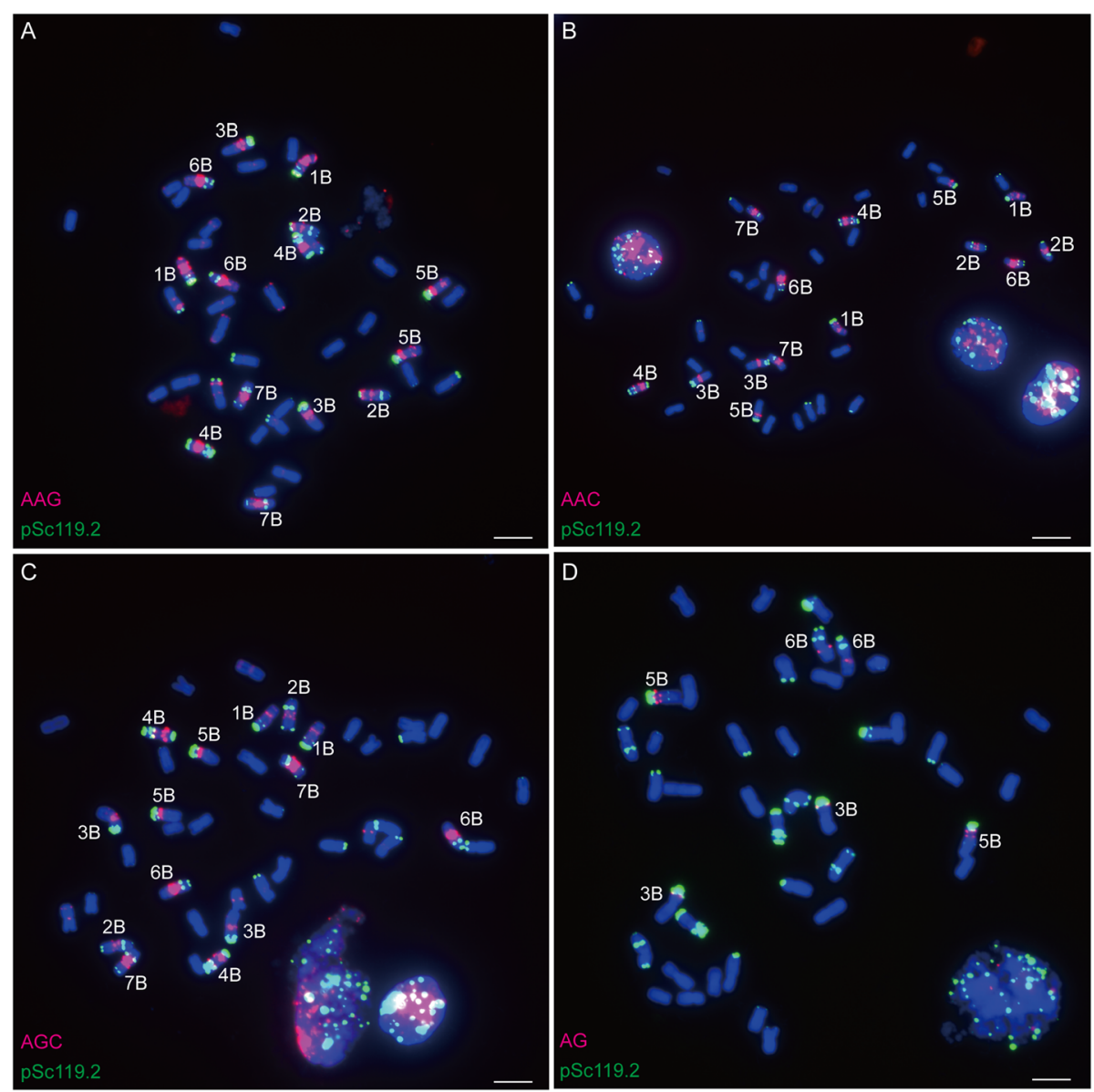

Fig. 2 Distribution of $(A A G)_{n},(A A C)_{n},(A G C)_{n}$ and $(A G)_{n}$ on metaphase chromosomes of bread wheat T. aestivum var. Chinese Spring. a: (AAG)n (red) and pSc119.2 (green); b: (AAC) $($ red) and pSc119.2 (green); c: (AGC) $($ red) and pSc119.2 (green); d: (AG) $n$ (red) and pSc119.2

(green). Bar $=10 \mu \mathrm{m}$

part of long arm of chromosome $5 \mathrm{~A}$, a weak signal in the centromeric region of chromosome $6 \mathrm{~A}$ and a strong signal in the pericentromeric region of the long arm of chromosome 7A (Fig. 4a and k). In Ae. tauschii, (AAC) only produced weaker spot-like signals in centromeric regions of chromosome 4D (Fig. 4c). In Ae. speltoides, strong signals were observed in the centromeric and pericentromeric regions of all the chromosomes ( $\mathrm{S}$ genome), which are weaker and fewer than those on chromosomes of the B genome in Chinese Spring (Fig. 4b and g). In wild emmer wheat (T. turgidum ssp. dicoccoides), the wild relative of durum wheat, strong condensed broad band signals were observed on both arms of chromosomes $1 \mathrm{~B}, 2 \mathrm{~B}, 4 \mathrm{~B}, 6 \mathrm{~B}$ and $7 \mathrm{~B}$, short arms of chromosome $5 \mathrm{~B}$ and pericentromeric regions of chromosome 3B; in addition to band-like signals, dotlike signals could also be observed on both arms of chromosomes $1 \mathrm{~B}, 2 \mathrm{~B}, 3 \mathrm{~B}, 4 \mathrm{~B}$ and $4 \mathrm{~A}$, on long arms of chromosomes $5 \mathrm{~B}, 6 \mathrm{~B}$ and $7 \mathrm{~A}$, and on short arms of $7 \mathrm{~B}$ and $2 \mathrm{~A}$ chromosomes (Fig. $4 \mathrm{~d}, \mathrm{~h}$ and $\mathrm{l}$ ). In domesticated emmer wheat (T. turgidum ssp. dicoccum), similar signal distribution patterns to those of wild emmer wheat were observed, except chromosomes 2B and 2A, which showed narrower band signals and fewer dot-like signals (Fig. 4e, i and $\mathrm{m}$ ).

Comparing the chromosomal distribution patterns of $(\mathrm{AAC})_{\mathrm{n}}$ between bread wheat and its diploid progenitors, obvious $(\mathrm{AAC})_{\mathrm{n}}$ sequence expansion was observed on chromosomes $1 \mathrm{~B}, 2 \mathrm{~B}, 7 \mathrm{~B}$ and $2 \mathrm{~A}$; sequence elimination was detected on chromosomes $1 \mathrm{~A}, 5 \mathrm{~A}, 6 \mathrm{~A}$ and $4 \mathrm{D}$; and both expansion and elimination were observed on chromosomes $2 \mathrm{~B}, 3 \mathrm{~B}, 6 \mathrm{~B}, 4 \mathrm{~A}$ and $7 \mathrm{~A}$ in bread wheat (Fig. 4). However, the distribution changes of $(\mathrm{AAC})_{\mathrm{n}}$ from progenitors to the bread wheat genome was mainly the sequence expansion in the $\mathrm{B}$ genome (especially in chromosomes $1 \mathrm{~B}, 2 \mathrm{~B}, 4 \mathrm{~B}, 6 \mathrm{~B}$ and $7 \mathrm{~B}$ ). Comparing the chromosomal distribution patterns of $(\mathrm{AAC})_{\mathrm{n}}$ between bread wheat and its tetraploid progenitors, sequence elimination was observed on $1 \mathrm{~B}, 3 \mathrm{~B}, 4 \mathrm{~B}, 5 \mathrm{~B}$ and $7 \mathrm{~B}$ chromosomes; whereas, both sequence expansion and 

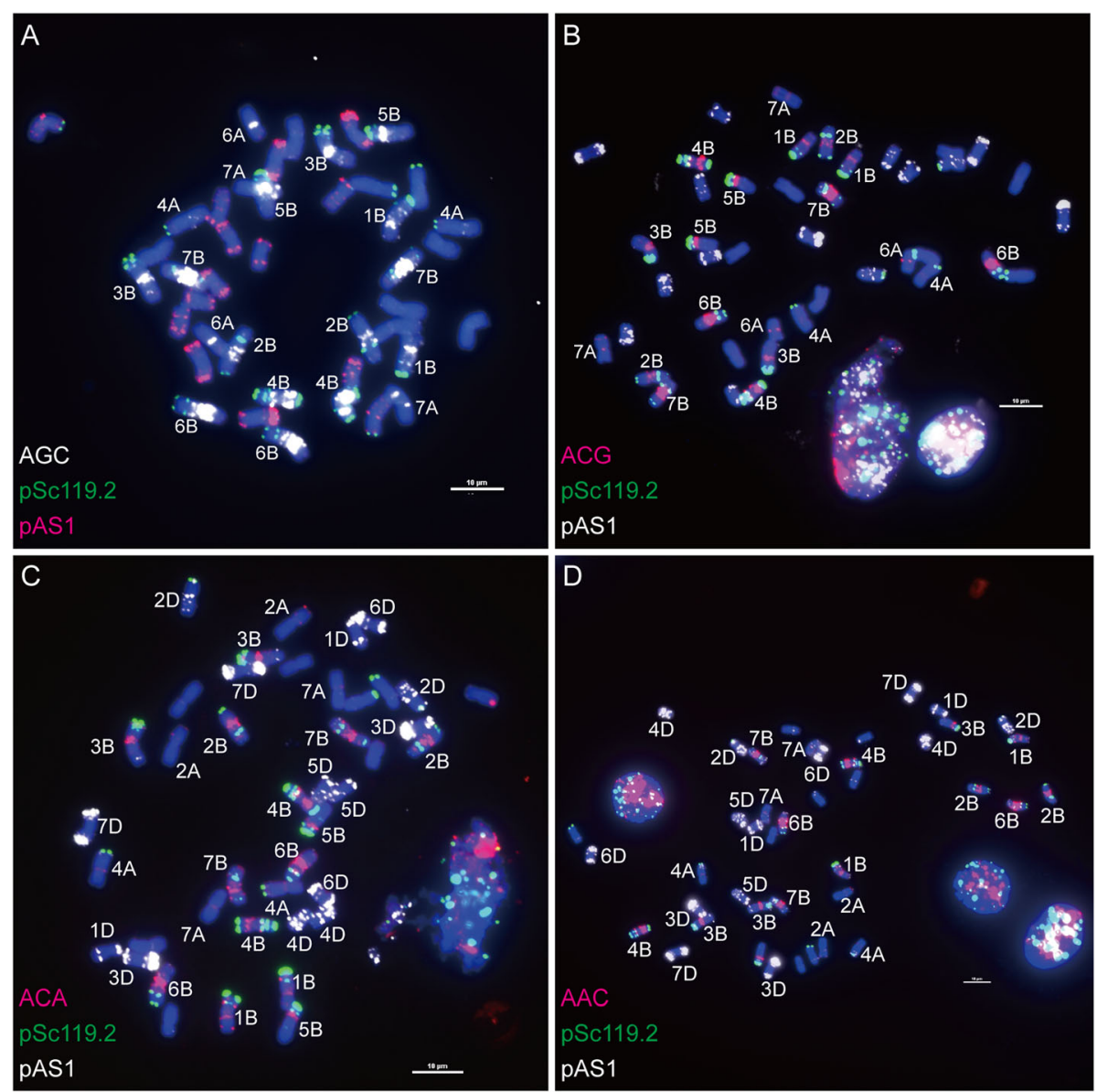

Fig. 3 Distribution of $(A G C)_{n}(A C G)_{n},(A C A)_{n}$ and $(A A C)_{n}$ on metaphase chromosomes of bread wheat T. aestivum var. Chinese Spring. a: (AGC)n (white), pSc119.2 (green) and pAS1 (red); b: (ACG) (red), pSc119.2 (green) and pAS1 (white) probe; c: (ACA)n (red), pSc119.2 (green) and pAS1

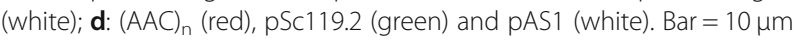

elimination were detected on $2 \mathrm{~B}$ chromosomes in bread wheat (Fig. 4, Additional files 1 and 2).

\section{The distribution patterns of $(A A G)_{n}$ on chromosomes of bread wheat and its progenitors}

In Chinese Spring, $(\mathrm{AAG})_{\mathrm{n}}$ showed strong signal distribution in centromeric and pericentromeric regions of all $\mathrm{B}$ genome chromosomes. Compared with the distribution of $(A A C)_{n},(A A G)_{n}$ were more distally located. In addition, unlike (AAC) $)_{n}$, obvious subtelomeric signals of $(\mathrm{AAG})_{\mathrm{n}}$ were present on chromosomes $1 \mathrm{~B}, 2 \mathrm{~B}$ and $3 \mathrm{~B}$, and a strong intercalary signal band could also be found on 5BS (Fig. 5f and j). There were sporadically weak $(A A G)_{n}$ signals in pericentromeric regions of chromosomes $2 \mathrm{~A}, 3 \mathrm{~A}$, and $4 \mathrm{~A}$ and the centromeric region of chromosome 5A and interstitial region of the chromosome 1A arm; apparent signals in the subtelomeric regions of chromosome $4 \mathrm{~A}$; and obvious telomeric signals on chromosome 7A (Fig. 5f and n). (AAG) $n$ showed weak signals in subtelomeric regions of chromosomes
1D and 7D, and pericentromeric regions of chromosome 2D (Fig. $5 \mathrm{f}$ and $\mathrm{p}$ ).

In T. urartu, the (AAG) motif produced two dot-like signals in the pericentromeric regions of $4 \mathrm{~A}$ and $5 \mathrm{~A}$ (Fig. $5 \mathrm{a}$ and k). In Ae. speltoides, the FISH signals of (AAG) were observed in the centromeric and pericentromeric regions of all the chromosomes, and they were slightly weaker than those of $(\mathrm{AAC})_{\mathrm{n}}$, except chromosome $5 \mathrm{~S}$ (Fig. 5b and g), while most signals were weaker than those in Chinese Spring. In Ae. tauschii, (AAG) $\mathrm{n}$ displayed signals in the pericentromeric regions of chromosomes 2D, 3D and 4D (Fig. 5c and o). In wild and emmer wheats, strong condensed band-like signals were observed in the pericentromeric regions of all chromosomes; dot-like signals could be detected on both arms of chromosome $3 \mathrm{~B}$, short arms of chromosomes $2 \mathrm{~B}$ and $7 \mathrm{~B}$, and long arms of chromosomes $3 \mathrm{~B}, 4 \mathrm{~B}, 5 \mathrm{~B}, 2 \mathrm{~A}$ and $4 \mathrm{~A}$ (Fig. $5 \mathrm{~d}, \mathrm{~h}$ and $\mathrm{l}$ ). In domesticated emmer wheat, broader band-like signals than wild emmer wheat were observed in the pericentromeric regions of all 

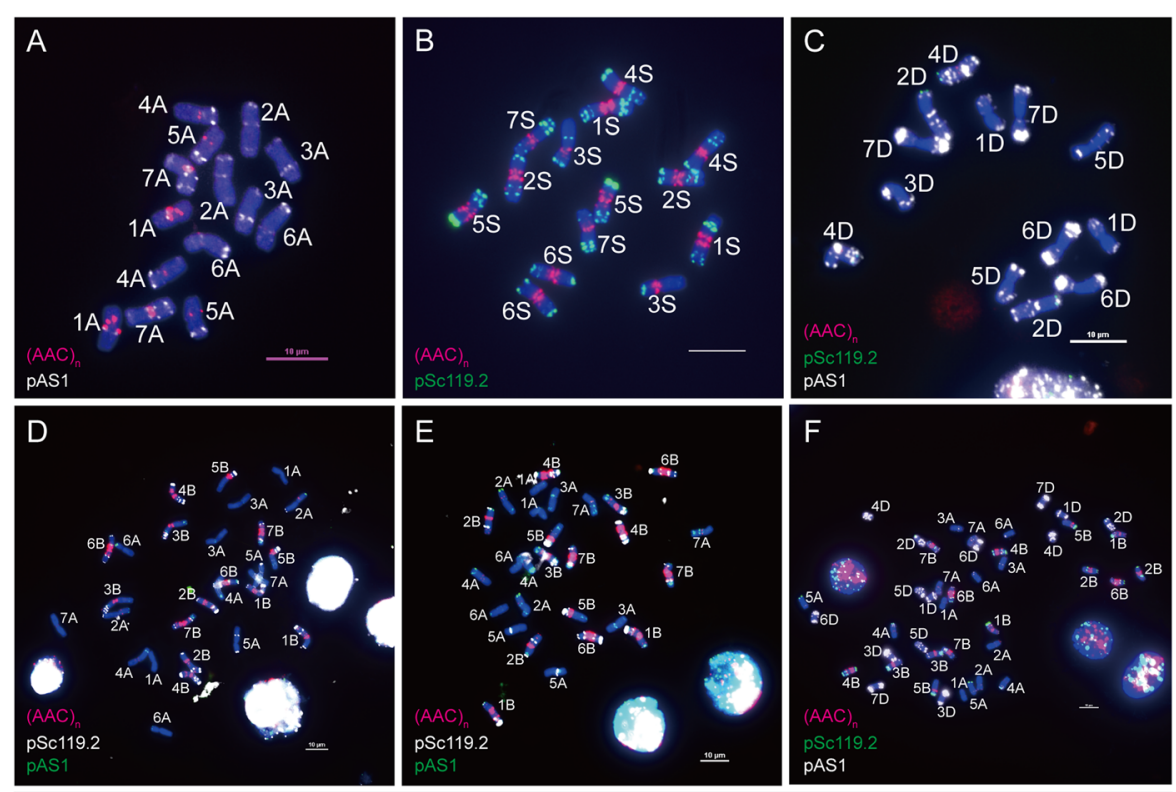

G

Ae. speltoids
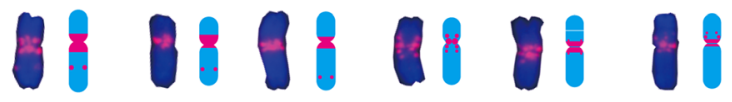

$$
\mathrm{H}
$$

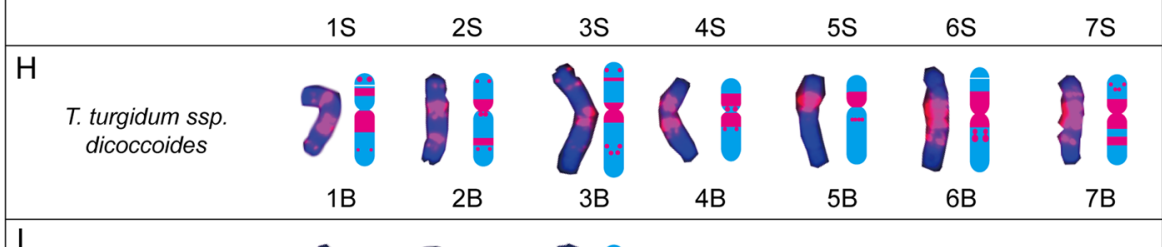

$$
\text { I }
$$

T. turgidum ssp.

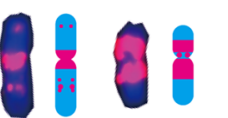

810

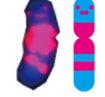

J

T. aestivum var.

Chinese spring
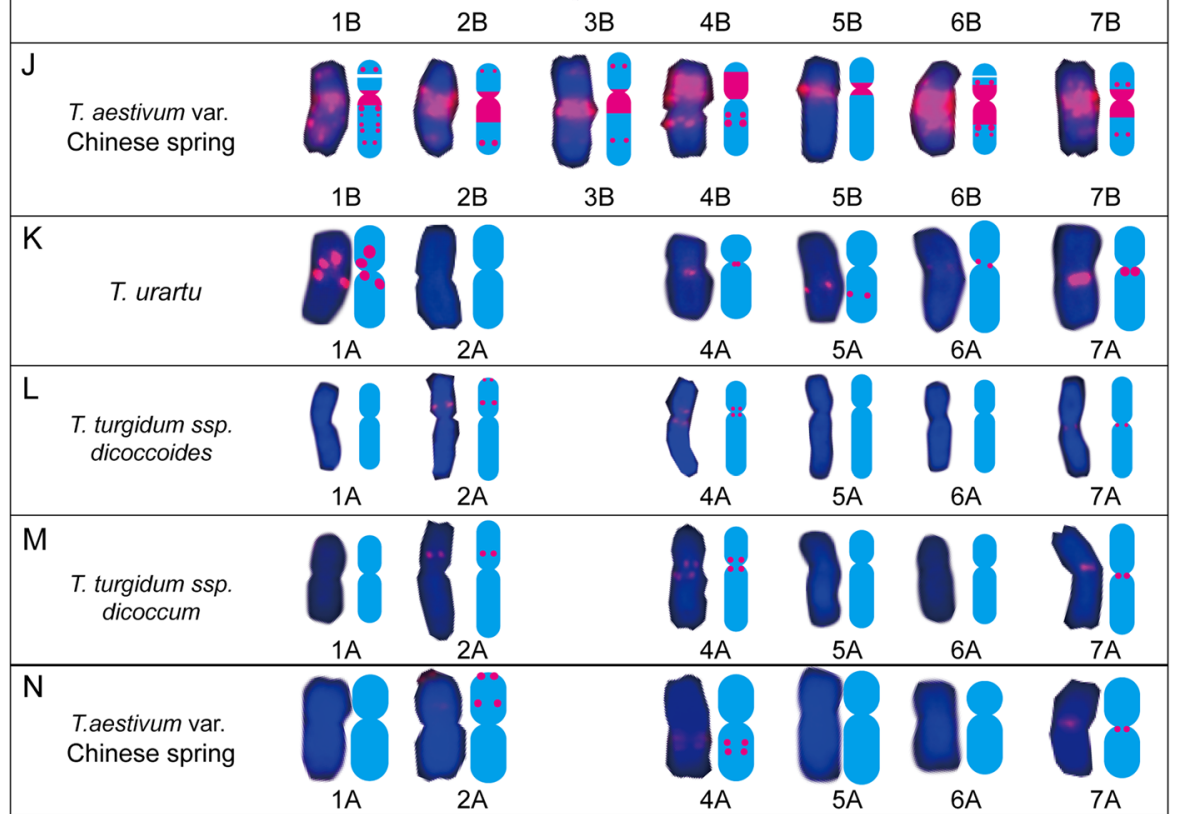

Fig. 4 (See legend on next page.) 


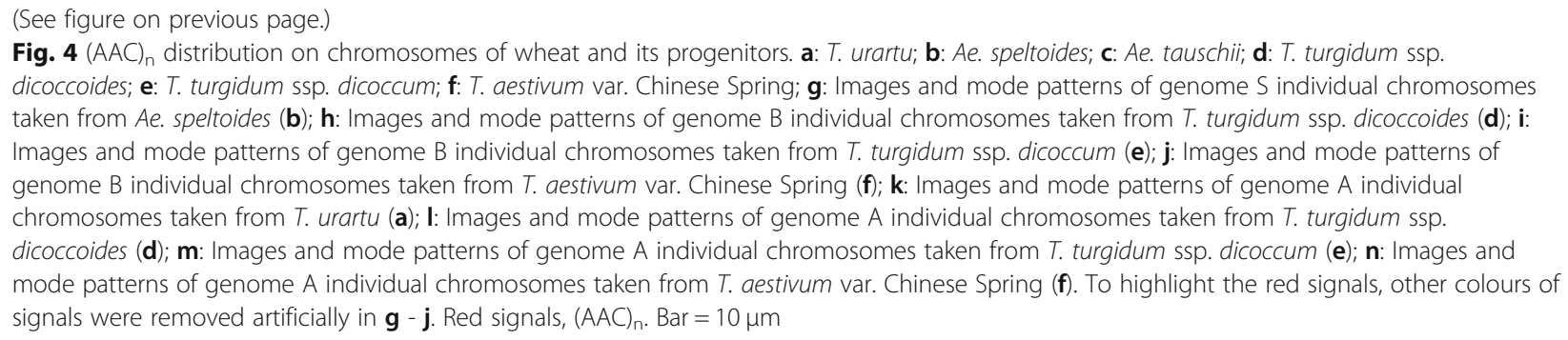

chromosomes; more dot-like signals than those of wild emmer wheat were observed on both arms of chromosomes $1 \mathrm{~B}, 2 \mathrm{~B}, 3 \mathrm{~B}$ and $7 \mathrm{~B}$, short arm of chromosome $6 \mathrm{~B}$, and long arms of chromosomes $4 \mathrm{~B}, 5 \mathrm{~B}, 2 \mathrm{~A}$ and $4 \mathrm{~A}$ (Fig. $5 e, i$ and $m)$.

Similar to $(A A C)_{n},(A A G)_{n}$ was mainly dispersed on $B$ genome chromosomes. The main changes in (AAG) distribution from diploid progenitors to the bread wheat genome were the sequence expansions on chromosomes $1 \mathrm{~B}, 2 \mathrm{~B}, 3 \mathrm{~B}, 4 \mathrm{~B}, 6 \mathrm{~B}, 7 \mathrm{~B}$ and $4 \mathrm{~A}$ and the sequence elimination of chromosomes $5 \mathrm{~B}, 2 \mathrm{D}, 3 \mathrm{D}$ and $4 \mathrm{D}$ during wheat formation. The main changes of (AAG) $)_{n}$ distribution from tetraploid progenitors to the bread wheat genome were the sequence expansions on all $\mathrm{B}$ and $\mathrm{A}$ genome chromosomes (Fig. 5, Additional files 1 and 2).

\section{The distribution patterns of the (AGC) $n$ motif in bread wheat and its progenitors}

In Chinese Spring, the FISH pattern of $(\mathrm{AGC})_{\mathrm{n}}$ on $\mathrm{B}$ genome chromosomes was more similar to $(A A C)_{n}$, but with lower signal density, especially on chromosomes $1 \mathrm{~B}$ and $2 \mathrm{~B}$ (Fig. $6 \mathrm{f}$ and $\mathrm{j}$ ); dot-like signals were detected in the pericentromeric regions of chromosomes $4 \mathrm{~A}, 6 \mathrm{~A}$ and $7 \mathrm{~A}$, and subtelomeric regions of chromosome 7A (Fig. $6 \mathrm{f}$ and $\mathrm{j}$ ), and no signals were detectable on $\mathrm{D}$ genome chromosomes (Fig. 6f). In Ae. speltoides, similar to the distribution patterns of $(\mathrm{AAC})_{\mathrm{n}}$ and $(\mathrm{AAG})_{\mathrm{n}}$, the $(A G C)_{n}$ motif signals were also concentrated in the pericentromeric regions, but with lower intensity (Fig. 6c and $\mathrm{g})$. No $(\mathrm{AGC})_{\mathrm{n}}$ signals were detectable in the diploid species T. urartu and Ae. tauschii (Fig. 6a and b). In wild emmer wheat, band-like signals were observed on the pericentromeric regions of chromosomes $2 \mathrm{~B}, 3 \mathrm{~B}, 5 \mathrm{~B}, 6 \mathrm{~B}$ and $7 \mathrm{~B}$; dot-like signals could be detected on both arms of chromosomes $1 \mathrm{~B}$ and $4 \mathrm{~B}$, long arms of chromosomes $2 \mathrm{~B}, 3 \mathrm{~B}$ and $6 \mathrm{~B}$, short arms of chromosome $7 \mathrm{~B}$, and pericentromeric regions of chromosomes $4 \mathrm{~B}$ and $7 \mathrm{~A}$ (Fig. $6 \mathrm{~d}, \mathrm{~h}$ and $\mathrm{k})$. In domesticated emmer wheat, band-like signals were observed on the pericentromeric regions of all B genome chromosomes, except chromosome 4B; dot-like signals were observed on both arms of chromosome $1 \mathrm{~B}, 3 \mathrm{~B}$, and $7 \mathrm{~B}$, short arms of chromosome $4 \mathrm{~A}$, long arms of chromosomes $2 \mathrm{~B}, 6 \mathrm{~B}, 6 \mathrm{~A}$ and $7 \mathrm{~A}$, and pericentromeric regions of chromosomes $4 \mathrm{~B}, 6 \mathrm{~B}, 4 \mathrm{~A}$ and 7A (Fig. 6e, i and l).

By comparison of the chromosomal distribution patterns of $(\mathrm{AGC})_{\mathrm{n}}$ between bread wheat and its progenitors, obvious sequence expansion of $(\mathrm{AGC})_{\mathrm{n}}$ was observed on chromosomes 1B-7B (especially 4B, 6B and $7 \mathrm{~B}), 4 \mathrm{~A}, 6 \mathrm{~A}$ and $7 \mathrm{~A}$; both expansion and elimination of $(\mathrm{AGC})_{\mathrm{n}}$ sequences were observed on chromosomes on $4 \mathrm{~B}$ and $5 \mathrm{~B}$ of bread wheat (Fig. 6, Additional files 1 and 2 ). In the progenitors of bread wheat, similar to (AAC) and $(\mathrm{AAG})_{\mathrm{n}},(\mathrm{AGC})_{\mathrm{n}}$ FISH signals were predominantly detected on $\mathrm{B}$ genome chromosomes and rarely detected on $\mathrm{A}$ and $\mathrm{D}$ genome chromosomes. The expansion of $(\mathrm{AGC})_{\mathrm{n}}$ along $\mathrm{B}$ genome chromosomes was also the main change during wheat formation.

\section{The distribution patterns of the (AG) $n$ motif in bread wheat and its progenitors}

Different from other SSRs, $(\mathrm{AG})_{\mathrm{n}}$ signals were only clustered in the pericentromeric regions of chromosomes $3 \mathrm{~B}, 5 \mathrm{~B}$ and $6 \mathrm{~B}$ in Chinese Spring (Fig. $7 \mathrm{f}$ and $\mathrm{j}$ ), and no detectable signals were observed on the other chromosomes. In Ae. speltoides, (AG) $)_{n}$ signals were observed in the pericentromeric or near the pericentromeric regions of chromosomes $2 \mathrm{~S}$ to $7 \mathrm{~S}$, and the distal regions of long arms of chromosomes $3 \mathrm{~S}$ and $5 \mathrm{~S}$, but there was no detectable signal on chromosome $1 \mathrm{~S}$ (Fig. $7 \mathrm{~b}$ and $\mathrm{g}$ ); in addition, spot-like signals were observed near the pericentromeric regions of chromosomes 2D, 3D and 4D in Ae. tauschii (Fig. 7c and k), even though no D genome chromosome located signals were observed in Chinese Spring (Fig. 7f and j). In wild and emmer wheat, spotlike signals were observed on the pericentromeric regions of chromosomes $1 \mathrm{~B}, 5 \mathrm{~B}$ and $6 \mathrm{~B}$, and short arms of chromosome 3B (Fig. 7d and h). In domesticated emmer wheat, a similar signal distribution pattern to those of wild emmer wheat was observed except on chromosome 6B (Fig. 7e and i).

In the comparison of the chromosomal distribution patterns of $(A G)_{n}$ between bread wheat and its progenitors, $(A G)_{n}$ sequence elimination was observed on chromosomes $2 \mathrm{~B}, 4 \mathrm{~B}, 6 \mathrm{~B}, 7 \mathrm{~B}, 2 \mathrm{D}, 3 \mathrm{D}$ and $4 \mathrm{D}$ in bread wheat; and both expansion and elimination were observed on 


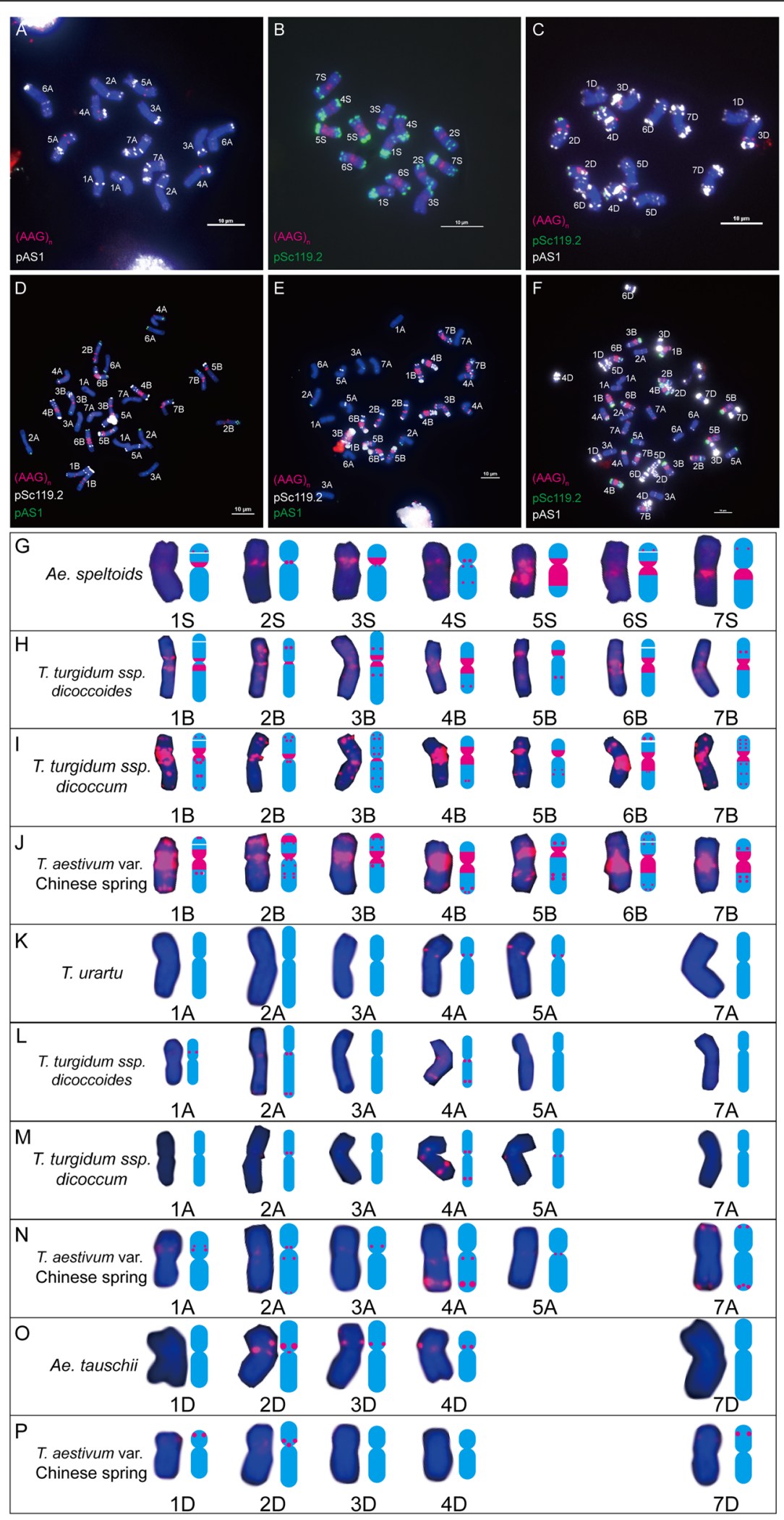

Fig. 5 (See legend on next page.) 


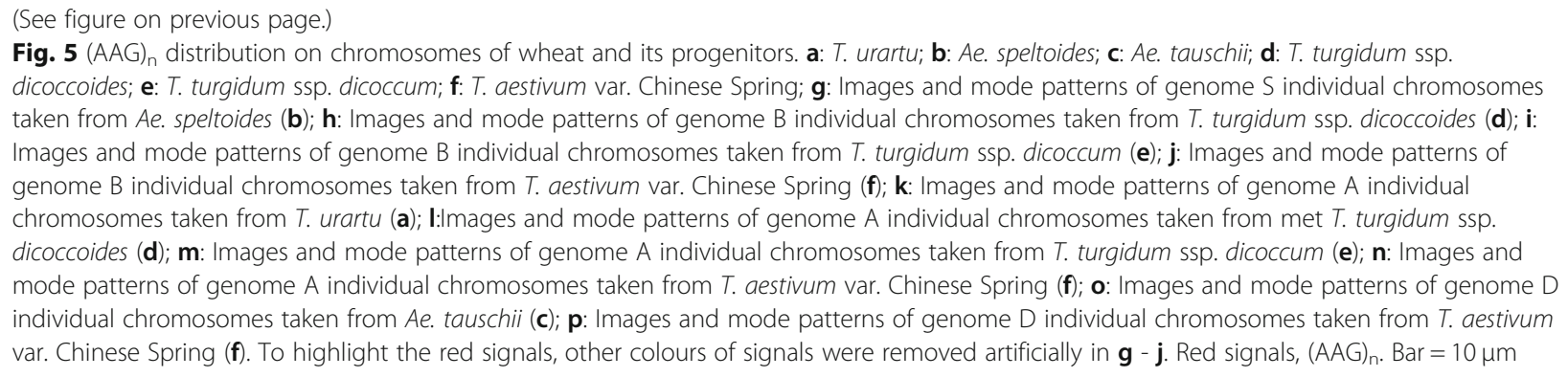

3B, 5B, and 6B chromosomes of wheat (Fig. 7, Additional files 1 and 2). The elimination of the $(A G)_{n}$ sequence in the $\mathrm{B}$ genome was the main changes during wheat formation.

\section{Discussion}

Bread wheat, an allohexaploid cereal crop, possesses a very large genome with over $80 \%$ of repetitive sequences $[14,19]$. Even though the whole genome sequence data of bread wheat and its two diploid progenitors (Ae. tauschii and T. urartu) are publicly available [14, 33$35]$, the accurate sequencing, assembly, and chromosomal localization of repetitive sequences remains challenging, especially for the unsequenced $\mathrm{B}$ genome donor. Moreover, the relationship between the $\mathrm{S}$ genome of Ae. speltoides and the B genome of durum and bread wheats is still being debated, even though Ae. speltoides is considered the most likely B donor $[15,36]$. SSRs, which are abundant components present in wheat, is an efficient tool to study genomic alterations in eukaryotes $[6,17,18,20,22,30]$. In this study, the distribution dynamics of SSRs on chromosomes of bread wheat and its progenitors were comprehensively investigated by FISH.

Short stretches of SSRs (20 $250 \mathrm{bp})$ are normally undetectable by FISH, and the FISH detectable regions should be the regions enriched in long stretches of SSR sequences. In this study, 21 SSR sequences were labeled (Table 1) and hybridized with the chromosomes of bread wheat Chinese Spring, and only 6 SSR sequences, $(\mathrm{AAC})_{\mathrm{n}},(\mathrm{AAG})_{\mathrm{n}},(\mathrm{ACA})_{\mathrm{n}},(\mathrm{AG})_{\mathrm{n}},(\mathrm{AGC})_{\mathrm{n}}$ and $(\mathrm{ACG})_{\mathrm{n}}$, displayed strong and stable FISH signals (Figs. 1, 2 and 3). This result suggested that these 6 SSRs were prone to forming long stretches of sequences in the wheat genome and could produce detectable FISH signals on chromosomes of bread wheat.

The selected SSRs, $(\mathrm{AAC})_{\mathrm{n}},(\mathrm{AAG})_{\mathrm{n}},(\mathrm{AG})_{\mathrm{n}}$ and $(\mathrm{ACG})_{\mathrm{n}}$ had already been used as FISH probes to study genetic diversity or genomic reconstruction either in wheat, wheat relatives or wheat progenitor species $[17$, $21,23,25-27,29-31,33,37-40]$, but had not been comprehensively compared among wheat and its diploid and tetraploid progenitors. In this study, a systematic study was performed to investigate the distribution patterns of different SSRs on the chromosomes of wheat and its diploid and tetraploid progenitors, obvious SSR signal changes were observed from diploid donor to hexaploid wheat, which support the previous studies that the wheat genome has underwent extensive changes during its polyploidization and evolution [16, 36]. In addition, stronger and wider FISH signals than previous studies were detected in this study, which might be caused by the difference of probe labeling method. Using a PCR method in the absence of template, rather than randomprimer labeling method or direct synthesized method [21-23, 25, 39], could produce longer probes and might reflect the actual location of large SSR clusters.

SSR sequences were not randomly distributed in wheat genomes, as their distribution on chromosomes depending on the motif, chromosome and genome, as demonstrated by Cuadrado et al. [21]. Although the size of SSR repeat units in wheat still needs to be confirmed, large SSR clusters could be located and compared in this study. In consistence with the studies that constitutive heterochromatic regions and SSRs are more abundant in the $\mathrm{B}$ genome chromosomes than those of $\mathrm{A}$ and $\mathrm{D}$ genomes $[14,36,41,42]$, most signals of $(\mathrm{AAC})_{\mathrm{n}},(\mathrm{AAG})_{\mathrm{n}}$, $(\mathrm{ACG})_{\mathrm{n}}$ and $(\mathrm{AG})_{\mathrm{n}}$ were located on the $\mathrm{B}$ genome chromosome, followed by A genome chromosomes, and were least likely to be found on D genome chromosomes, and each SSR has its unique distribution patterns on different genomes and different chromosomes (Figs. 4, 5, 6 and 7). The results suggested that there would be a high heterogeneity of SSRs in wheat genome, especially $B$ genome.

To integrate our SSR FISH results with their physical position in the genomes, the physical position of $(\mathrm{AAC})_{\mathrm{n}},(\mathrm{AAG})_{\mathrm{n}},(\mathrm{AGC})_{\mathrm{n}}$, and $(\mathrm{AG})_{\mathrm{n}}$ were predicted using the web server B2DSC (http://mcgb.uestc.edu.cn/ b2dsc) (Additional files 3, 4, 5 and 6) [27]. The prediction results indicated that high copy number SSR tandem repeats prone to cluster on chromosomes of wheat, especially the centromeric and pericentromeric regions of B genome chromosomes. Low copy number SSR repeats were more likely dispersed in the genomes of Ae. tauschii and T. urartu, which were not long enough to be detected by FISH, especially for the $(\mathrm{AG})_{\mathrm{n}}$ 

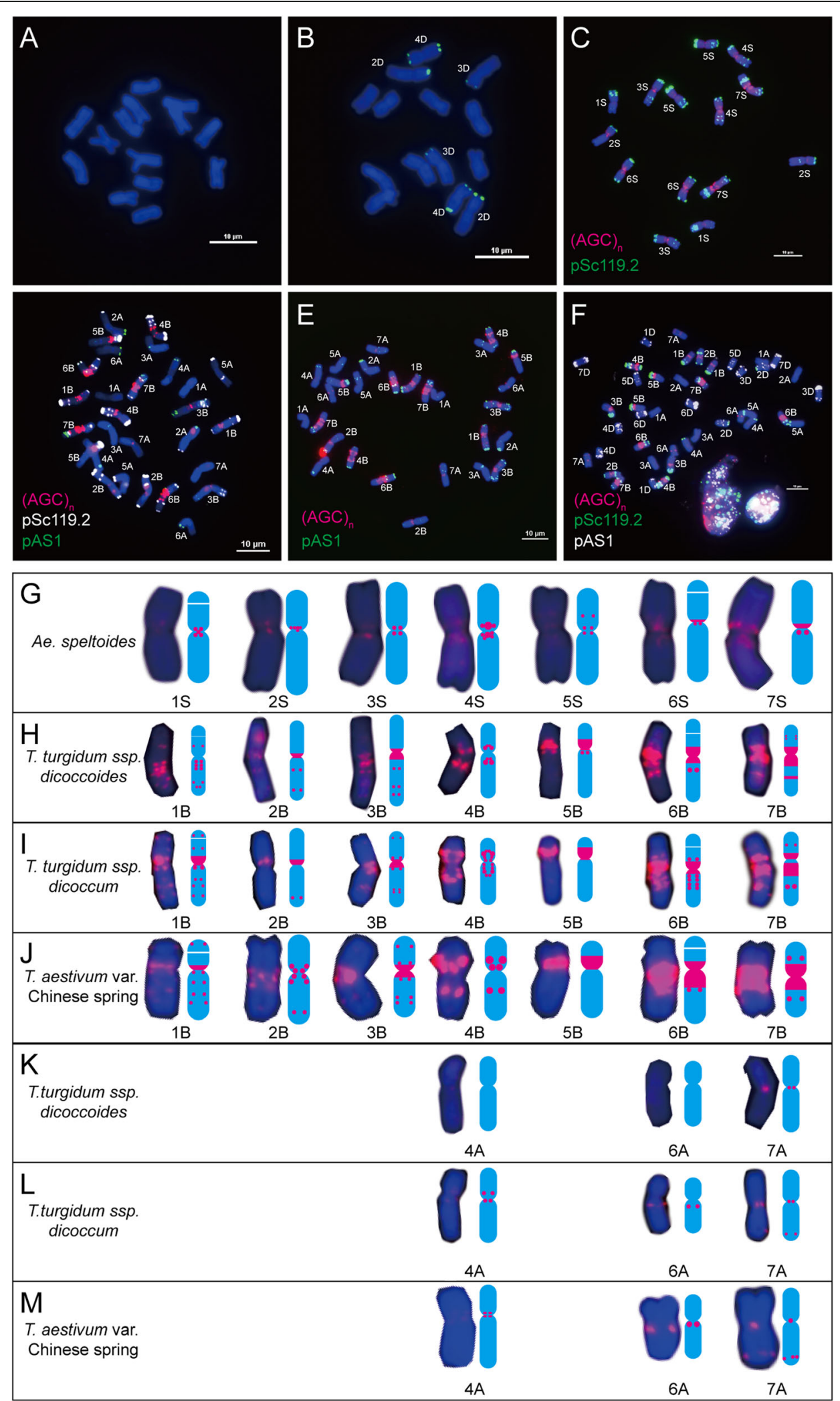

Fig. 6 (See legend on next page.) 


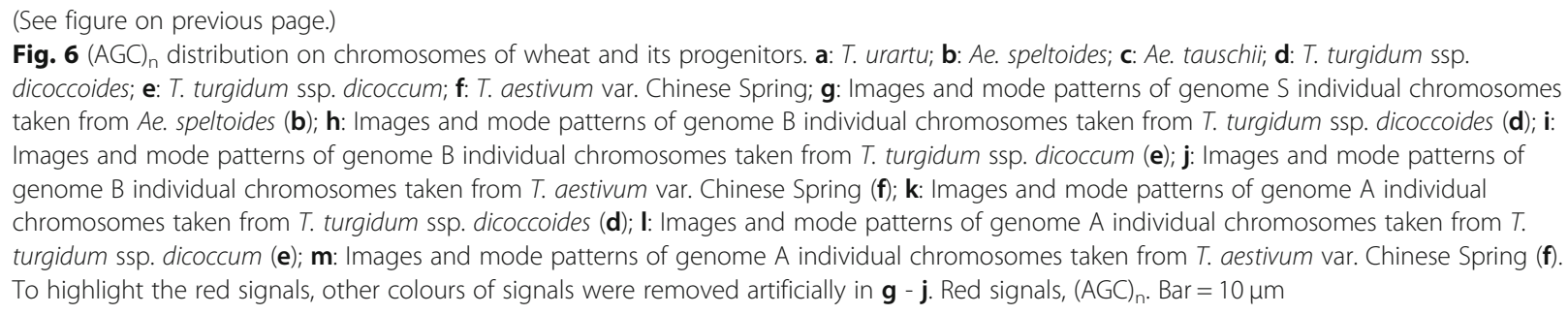

sequence (Additional files 3, 4, 5 and 6). As the Ae. speltoides has not been sequenced yet, the physical location of SSR sequences in the genome was not analyzed here. As expected, the distribution of large SSR clusters in the predicted physical map was consistent with the results of FISH analysis, but the SSR sequences mapped by FISH were more concentrated, which showed the longer and abundant SSR sequence locations. In addition, more SSR repeats prone to form small clusters and widely distributed in genome, especially in genomes of Ae. tauschii and T. urartu. These small SSR clusters were not long enough to be detected by FISH (Additional files 3, 4, 5 and 6).

Following polyploidization, the wheat genome has undergone massive genomic rearrangements, including chromosome variation, sequence amplification and elimination [7, 11-13, 16]. To trace its genome evolution dynamics during its formation and evolution, karyotypes of wheat and its diploid and tetraploid progenitors based on our four SSR FISH results were constructed, and differences were analysed in terms of the abundance and localization of SSR motifs between different genomes and chromosomes. During wheat formation, compared with its progenitors, more SSR FISH signal changes were detected as SSR sequence expansion and/or elimination on B genome chromosomes (judged by the rough strength and number of FISH signals). Briefly and importantly, during wheat formation, the main distribution changes of our studied four SSRs from diploid progenitors to the bread wheat genome should be the sequence expansion on chromosomes $1 \mathrm{~B}, 2 \mathrm{~B}, 4 \mathrm{~B}, 6 \mathrm{~B}$ and $7 \mathrm{~B}$ for $(A A C)_{n}$; the sequence expansion on chromosomes $1 B$, $2 \mathrm{~B}, 3 \mathrm{~B}, 4 \mathrm{~B}, 6 \mathrm{~B}, 7 \mathrm{~B}$ and $4 \mathrm{~A}$ and the sequence elimination on chromosomes $5 \mathrm{~B}, 2 \mathrm{D}, 3 \mathrm{D}$ and $4 \mathrm{D}$ for $(\mathrm{AAG})_{n}$; the sequence expansion on chromosomes 1B-7B (especially $4 \mathrm{~B}, 6 \mathrm{~B}$ and $7 \mathrm{~B}), 4 \mathrm{~A}, 6 \mathrm{~A}$ and $7 \mathrm{~A}$ and both expansion and elimination on chromosomes $4 \mathrm{~B}$ and $5 \mathrm{~B}$ for $(\mathrm{AGC})_{n}$ and the sequence elimination on chromosomes $2 \mathrm{~B}, 4 \mathrm{~B}, 6 \mathrm{~B}, 7 \mathrm{~B}, 2 \mathrm{D}, 3 \mathrm{D}$ and $4 \mathrm{D}$; and both expansion and elimination on chromosomes $3 \mathrm{~B}, 5 \mathrm{~B}$, and $6 \mathrm{~B}$ for $(\mathrm{AG})_{\mathrm{n}}$. These results suggested that SSR sequences preferred to move and/or amplify around their original locations rather than different genomes or chromosomes during wheat formation. This phenomenon could be explained because variability of SSRs in the genome is primarily the result of slipped-strand mispairing followed by replication and recombination, or repair errors, which could change the lengths of microsatellites [43]. Among the four SSR probes, signal changes of (AAG) $)_{n}$ was the biggest across the $B$ genome chromosomes, followed by $(A A C)_{n}$, $(\mathrm{ACG})_{\mathrm{n}}$ and $(\mathrm{AG})_{\mathrm{n}}$ (Figs. 4, 5, 6 and 7), which suggested that different SSRs evolved at different speed across the B genome chromosomes. For $(\mathrm{AAC})_{\mathrm{n}}$, signal changes on $1 \mathrm{~B}$, $4 \mathrm{~B}, 6 \mathrm{~B}$ and $7 \mathrm{~B}$ were larger than those on $2 \mathrm{~B}, 3 \mathrm{~B}$ and $5 \mathrm{~B}$; For $(\mathrm{AAG})_{\mathrm{n}}$, signal changes on $\mathrm{BB}, 4 \mathrm{~B}, 5 \mathrm{~B}$ and $7 \mathrm{~B}$ were larger than those on $2 \mathrm{~B}, 3 \mathrm{~B}$ and $6 \mathrm{~B}$; For $(\mathrm{ACG})_{\mathrm{n}}$, signal changes on $3 \mathrm{~B}, 4 \mathrm{~B}, 5 \mathrm{~B}, 6 \mathrm{~B}$ and $7 \mathrm{~B}$ were larger than those on $1 \mathrm{~B}$ and $2 \mathrm{~B}$. These results is consistent with the view that genome differentiation during wheat allopolyploidization from $\mathrm{S}$ to $\mathrm{B}$ proceeds at different speeds over the chromosomes, which was revealed by genome-wide exon sequencing and resultant phylogenetic analysis [36].

The origin of the $\mathrm{B}$ genome of wheat had been debated by researchers for a very long time, as it evolved "at a higher rate of evolution" than the A and D genome, the $\mathrm{B}$ genome of wheat is now more different from $\mathrm{S}$ genome of Ae. speltoides [15, 36], which was also elucidated in this study. But even so, most SSR FISH signals on chromosomes of Ae. speltoides could be found in chromosomes of the bread wheat (Figs. 4, 5, 6 and 7), which supports the viewpoint that Ae. speltoides is likely to be the direct donor of all $\mathrm{B}$ genome chromosomes of wheat $[15,36]$. Moreover, more sequence changes were detected between wheat and its diploid progenitors rather than between wheat and its tetraploid progenitors, and the result suggested that the genome shock brought by the first hybridization event might be larger than the second hybridization event during wheat formation.

Revealed by phylogenetic analysis and FISH, centromeric satellites in wheat genome have undergone rapid changes in the three subgenomes and satellite signals decreased from diploid to hexaploid wheat [44]. In this study, it is obvious that the SSR sequence expansion occurred predominately in the centromeric and pericentromeric regions of $\mathrm{B}$ genome chromosomes during wheat formation, despite the SSR copy number variation in the centromeric region was not precisely calculated. These results suggested that the wheat centromeric and pericentromeric regions were sensitive to "genome shock" and evolved rapidly during the evolution of wheat. All of 


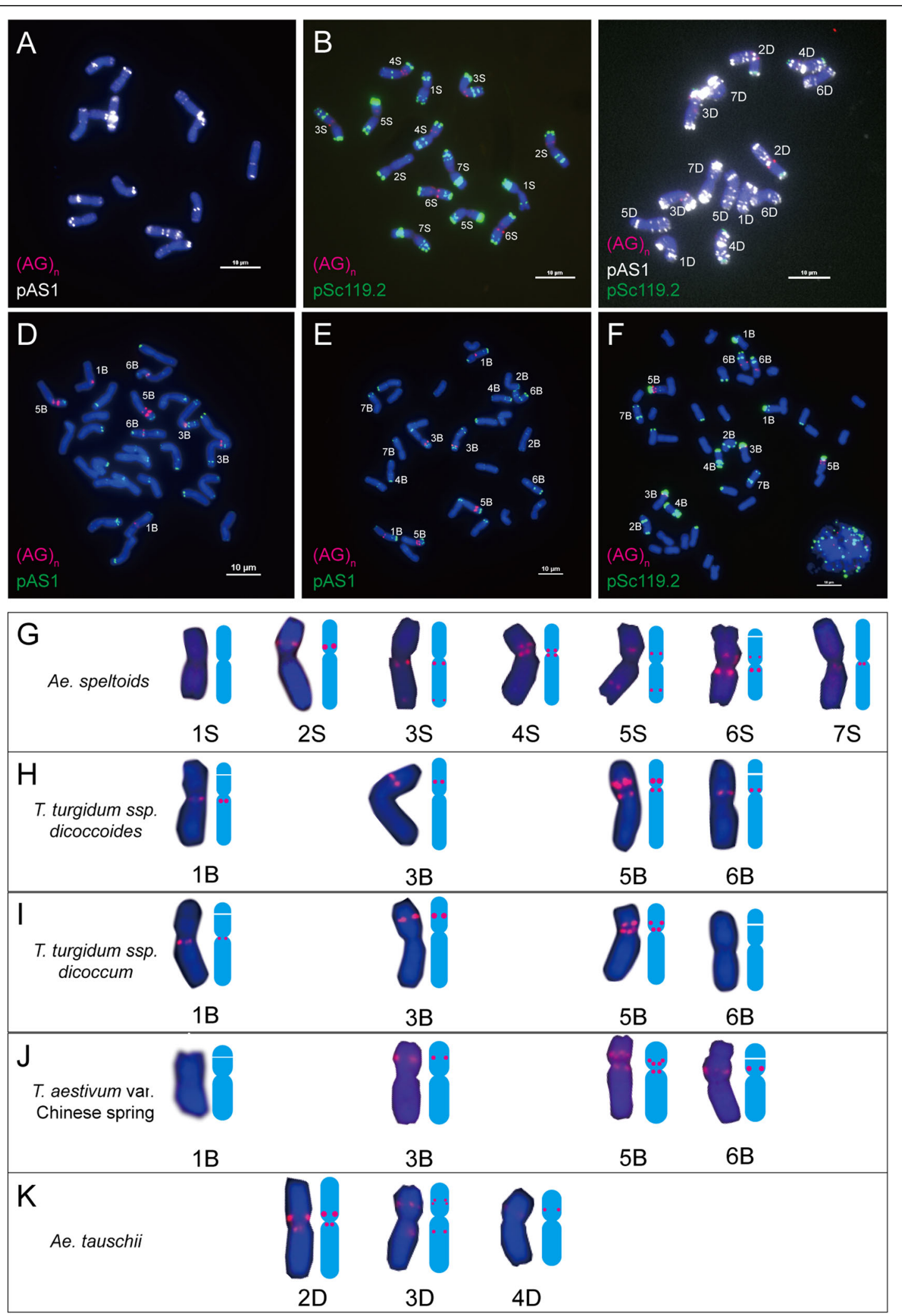

Fig. 7 (See legend on next page.) 
(See figure on previous page.)

Fig. $7(\mathrm{AG})_{n}$ distribution on chromosomes of wheat and its progenitors. a: T. urartu; b: Ae. speltoides; c: Ae. tauschii; d: T. turgidum ssp. dicoccoides; e: T. turgidum ssp. dicoccum; f: T. aestivum var. Chinese Spring; $\mathbf{g}$ : Images and mode patterns of genome $\mathrm{S}$ individual chromosomes taken from Ae. speltoides (b); $\mathbf{h}$ : images and mode patterns of genome B individual chromosomes taken from T. turgidum ssp. dicoccoides (d); $\mathbf{i}$ : Images and mode patterns of genome B individual chromosomes taken from T. turgidum ssp. dicoccum (e); j: Images and mode patterns of genome B individual chromosomes taken from T. aestivum var. Chinese Spring (f); $\mathbf{k}$ : Images and mode patterns of genome D individual chromosomes Ae. tauschii (c). To highlight the red signals, other colours of signals were removed artificially in $\mathbf{g}$ - j. Red signals, $(\mathrm{AG})_{n}$. Bar $=10 \mu \mathrm{m}$

these findings support the idea that the wheat genome is a dynamic system with a high level of plasticity [44], and a changing sequence repertoire shaped by sequence losses and expansion.

Our SSR FISH results indicated that the genome of wheat has evolved substantially following its polyploidization, and the rearrangement of SSRs might be important for facilitating wheat genome evolution and stabilizing chromosomes of different subgenomes. To address this, more work needs to be performed, such as the investigation of newly formed wheat species or relatives by more SSR FISH. Moreover, new studies might uncover the underlying mechanisms responsible for the widescale genome rearrangement in polyploids.

\section{Conclusion}

We investigated the genome evolution by comprehensively comparing the distribution patterns of $(\mathrm{AAC})_{\mathrm{n}},(\mathrm{AAG})_{\mathrm{n}}$, $(\mathrm{AGC})_{\mathrm{n}}$ and $(\mathrm{AG})_{\mathrm{n}}$ with FISH in bread wheat and its progenitors T. urartu, Ae. speltoides, Ae. tauschii, T. dicocoides and $T$. dicoccum. Obvious SSR signal changes were observed from diploid donor to hexaploid wheat in this study, especially SSR sequence expansion happened in the pericentromeric and centromeric regions of B genome chromosomes. The results suggested SSRs were efficient tools for tracing wheat genome polyploidization and evolution. The $B$ genome of wheat, especially the centromeric and pericentromeric regions of which, might be more sensitive to "genome shock" and evolved rapidly during the course of bread wheat formation, which further demonstrated the viewpoint that the B genome of bread wheat was more enriched in SSR sequences and evolved "at a higher rate of evolution" than the A and D genome $[15,36]$.

\section{Methods}

\section{Materials}

Plant materials used in this study included $T$. urartu $\left(2 \mathrm{n}=2 \mathrm{x}=14, \mathrm{~A}^{\mathrm{u}} \mathrm{A}^{\mathrm{u}}\right)$, Ae. speltoides $(2 \mathrm{n}=2 \mathrm{x}=14, \mathrm{SS})$, Ae. tauschii $(2 \mathrm{n}=2 \mathrm{x}=14, \mathrm{DD})$, wild tetraploid emmer wheat $T$. dicocoides $\left(2 \mathrm{n}=4 \mathrm{x}=28, \mathrm{~A}^{\mathrm{u}} \mathrm{A}^{\mathrm{u}} \mathrm{BB}\right)$, cultivated emmer wheat $T$. dicoccum $\left(2 \mathrm{n}=4 \mathrm{x}=28, \mathrm{~A}^{\mathrm{u}} \mathrm{A}^{\mathrm{u}} \mathrm{BB}\right)$, and $T$. aestivum var. Chinese Spring $(2 \mathrm{n}=(2 \mathrm{n}=6 \mathrm{x}=42$, AABBDD). The source of all the materials have been listed in Additional file 7.

\section{The screening of FISH positive SSR probes}

Bread wheat Chinese Spring was used to screen FISH positive SSR probes. Before performing FISH, the whole genome sequence of wheat cv. Chinese Spring (IWGSC RefSeqv1.0) was downloaded from URGI (https://wheaturgi.versailles.inra.fr/Seq-Reposi tory/Assemblies) and analysed using Tandem Repeats Finder version 4.09 with default parameters (http://tandem.bu.edu/trf/trf.basic. submit.html) [32]. SSR motifs repeated more than 5 times were chosen to hybridize with mitotic chromosomes of bread wheat.

\section{The preparation of SSRs probes}

SSR sequences were prepared using a PCR method in the absence of template, which is similar to the preparation of the telomere-specific probes [45]. Primers used to prepare the SSR probes were designed using primer 5.0 software and synthesized by the Shanghai Sangon Biological Engineering Technology Engineering Service Co., Ltd. and they are listed in Table 1. Briefly, SSRs sequences were prepared by PCRs that were carried out in a $100 \mu \mathrm{L}$ PCR system: $10 \mu \mathrm{L}$ of $10 \times$ PCR buffer, 2 units of Taq polymerase (Takara Bio, Shiga, Japan), $200 \mu \mathrm{M}$ for each dNTP and $200 \mathrm{nM}$ for each primer. Amplification consisted of 10 cycles each consisting of $1 \mathrm{~min}$ at $94{ }^{\circ} \mathrm{C}, 30 \mathrm{~s}$ at $55^{\circ} \mathrm{C}$, and $1 \mathrm{~min}$ at $72{ }^{\circ} \mathrm{C}$, followed by 30 cycles each consisting of $1 \mathrm{~min}$ at $94{ }^{\circ} \mathrm{C}, 30 \mathrm{~s}$ at $60{ }^{\circ} \mathrm{C}, 90 \mathrm{~s}$ at $72{ }^{\circ} \mathrm{C}$, and one final step of $5 \mathrm{~min}$ at $72{ }^{\circ} \mathrm{C}$. Smear DNA bands should be detected using $1.4 \%$ agarose gel electrophoresis; and if not, then a second round of PCR was performed under the same conditions, using $3 \mu \mathrm{L}$ of PCR products from the first round of PCR as template.

The probe labelling was conducted as previously described earlier [38]. The labelling system included $10 \mu \mathrm{L}$ of PCR product described above, $2 \mu \mathrm{L}$ of nick translation buffer, $2 \mu \mathrm{L}$ of dNTP $(-\mathrm{dCTP})$ mix, $0.5 \mu \mathrm{L}$ of Texas Red5 -dCTP $(1 \mathrm{mM}), 0.5 \mu \mathrm{L}$ of DNase I $(100 \mathrm{mU} / \mu \mathrm{L})$, and $5 \mu \mathrm{L}$ of DNA polymerase I $(10 \mathrm{U} / \mu \mathrm{L})$.

The repetitive sequence $\mathrm{pSc} 119.2$, originally isolated from Secale cereale by McIntyre et al. [37], and pAs1, originally isolated from Ae. tauschii by Nagaki et al. [46], were labelled to identifying the $\mathrm{B}$ and $\mathrm{D}$ genome chromosomes of wheat, respectively.

\section{Chromosome preparation and FISH}

Seeds were germinated on moist filter paper at $25^{\circ} \mathrm{C}$, and root tips of $1-2 \mathrm{~cm}$ in length were excised and treated 
with $\mathrm{N}_{2} \mathrm{O}$ for $2 \mathrm{~h}$ at room temperature before fixing in ethanol-acetic acid (3:1). Chromosome spread preparation and FISH were performed as previously described earlier [38]. Briefly, root tips were digested at $37^{\circ} \mathrm{C}$ for $1 \mathrm{~h}$ in an enzyme solution of $0.5 \%$ of pectolyase Y-23 (Kikkoman Co., Tokyo, Japan) and $1 \%$ cellulose Onozuka R-10 (Yakult Honsha Co., Ltd. Minato-ku, Tokyo, Japan), and dropped onto the slides. Air-dried slides were cross linked by exposure to UV light, then denatured at $100^{\circ} \mathrm{C}$ for 5 min with $6 \mu \mathrm{L}$ of diluted probe mix on the spreads. After hybridization overnight at $55^{\circ} \mathrm{C}$, the slides were washed with $2 \times$ SSC and counterstained with DAPI. Slides were examined using a Nikon Ni-E fluorescence microscope and photographed with a Nikon DS-Ri2 camera system (Nikon CEE GmbH, Wien, Austria).

\section{Physical mapping of SSR sequences}

To predict the physical location of SSR sequences, the SSR motifs (20 repeat units) were blasted against the genomes of wheat, T. urartu and Ae. tauschii respectively using B2DSC (http://mcgb.uestc.edu.cn/b2dsc) with default parameters [27].

\section{Supplementary Information}

The online version contains supplementary material available at https://doi. org/10.1186/s12864-020-07364-6.

Additional file 1. SSR sequence dynamics observed between wheat and its diploid progenitors.

Additional file 2. SSR sequence dynamics observed between wheat and its tetroploid progenitors.

Additional file 3. Physical mapping of $(A A C)_{n}$ on chromosomes of wheat and its diploid progenitors by using the web server B2DSC (http:// mcgb.uestc.edu.cn/b2dsc) with default parameters for the blast and filter steps [27]. Yellow bars, the distribution of Oligo-CCS1 corresponding to the positions of centromeres of wheat. Blue-to-red bars, the number of HSPs per Mbp of SSR sequences (20 repeat units).

Additional file 4. Physical mapping of (AAG) $n$ on chromosomes of wheat and its diploid progenitors by B2DSC, using default parameters for the blast and filter steps. Yellow bars, the distribution of Oligo-CCS1 corresponding to the positions of centromeres of wheat. Blue-to-red bars, the number of HSPs per Mbp of SSR sequences (20 repeat units).

Additional file 5. Physical mapping of (AGC) $n$ on chromosomes of wheat and its diploid progenitors by B2DSC, using default parameters for the blast and filter steps. Yellow bars, the distribution of Oligo-CCS1 corresponding to the positions of centromeres of wheat. Blue-to-red bars, the number of HSPs per Mbp of SSR sequences (20 repeat units).

Additional file 6. Physical mapping of $(A G)_{n}$ on chromosomes of wheat and its diploid progenitors by B2DSC, using default parameters for the blast and filter steps. Yellow bars, the distribution of Oligo-CCS1 corresponding to the positions of centromeres of wheat. Blue-to-red bars, the number of HSPs per Mbp of SSR sequences (20 repeat units).

Additional file 7. The accession list of wheat and its progenitor materials in this study.

\section{Abbreviations}

SSR: Simple sequence repeat; FISH: Fluorescence in situ hybridization; PCR: Polymerase chain reaction; DAPI: 4',6-diamidino-2-phenylindole

\section{Acknowledgments}

We appreciate Dr. Yiwen Li and Dr. Tiaoguo An (Institute of Genetics and Developmental Biology, Chinese Academy of Sciences) for providing some plant materials.

\section{Authors' contributions}

Z.H., C.F. and Y.Z. initiated and designed the experiments. Y.Z. performed the research and wrote the paper. Y.Z., X.Z., F.H., Y.C., C.F. and Z.H. interpreted and discussed the results and revised the manuscript. R.W. helped on advising the graduate research, interpreting and discussing data, and revising manuscript. All authors have read and approved the manuscript.

\section{Funding}

This research was founded by National Key Research and Development Plan from Ministry of Science and Technology of China (2016YFD0102003-10), the National Science Foundation of China (31870349 and 31170209), and an Open Research Project (PCCE-KF-2020-02) from State Key Laboratory of Plant Cell and Chromosome Engineering, Institute of Genetics and Developmental Biology, Chinese Academy of Sciences. The funding bodies played no role in the design of the study and collection, analysis, and interpretation of data and in writing the manuscript.

\section{Availability of data and materials}

The datasets analysed during the current study are available in the repository of European Bioinformatics Institute (EMBL-EBI, https://www.ebi.ac.uk/), with accession number GCA_900519105. All the other data, including SSR primers used for probe labeling, the summary of the SSR sequence dynamics detected by FISH, the physical position of SSR sequences predicted using bioinformatics method and the source of all species studied here, can be found in the article itself and its supplementary data.

Ethics approval and consent to participate

Not applicable.

\section{Consent for publication}

Not applicable.

\section{Competing interests}

The authors declare that they have no competing interests.

\section{Author details}

${ }^{1}$ State Key Laboratory of Plant Cell and Chromosome Engineering, Institute of Genetics and Developmental Biology, Innovation Academy for Seed Design, Chinese Academy of Sciences, Beijing 100101, China. ${ }^{2}$ College of Agriculture, Yangtze University, Jingzhou 434000, Hubei, China. ${ }^{3}$ United States Department of Agriculture, Agricultural Research Service, Forage and Range Research Laboratory, Utah State University, Logan, UT 84322-6300, USA. ${ }^{4}$ College of Agriculture, University of Chinese Academy of Sciences, Beijing 100049, China.

Received: 20 August 2020 Accepted: 30 December 2020

Published online: 14 January 2021

\section{References}

1. Blanc G, Wolfe KH. Widespread paleopolyploidy in model plant species inferred from age distributions of duplicate genes. Plant Cell. 2004;16(7): 1667-78.

2. Toda E, Okamoto T. Polyspermy in angiosperms: its contribution to polyploid formation and speciation. Mol Reprod Dev. 2019;87:374-9.

3. Feldman M, Levy AA. Allopolyploidy - a shaping force in the evolution of wheat genomes. Cytogenet Genome Res. 2015;109(1-3):250-8.

4. Bird KA, VanBuren R, Puzey JR, Edger PP. The causes and consequences of subgenome dominance in hybrids and recent polyploids. New Phytol. 2018; 220(1):87-93.

5. Feldman M, Levy AA. Genome evolution due to allopolyploidization in wheat. Genetics. 2012;192(3):763-74.

6. Li Q, Rana K, Xiong Z, Ge X, Li Z, Song H, et al. Genetic and epigenetic alterations in hybrid and derived hexaploids between Brassica napus and B. oleracea revealed by SSR and MSAP analysis. Acta Physiol Plant. 2019;41(5):61. 
7. Feldman M, Levy AA. Genome evolution in allopolyploid wheat - a revolutionary reprogramming followed by gradual changes. J Genet Genomics. 2009;36(9):511-8.

8. Li LF, Liu B. Recent advances of plant polyploidy and polyploid genome evolution. Scientia Sinica Vitae. 2019;49(4):327-37.

9. Adams KL, Percifield R, Wendel JF. Organ-specific silencing of duplicated genes in a newly synthesized cotton allotetraploid. Genetics. 2004;168(4): 2217-26.

10. Bento M, Gustafson P, Viegas W, Silva M. Genome merger: from sequence rearrangements in triticale to their elimination in wheat-rye addition lines. Theor Appl Genet. 2010;121(3):489-97.

11. Kashkush K, Feldman M, Levy AA. Gene loss, silencing and activation in a newly synthesized wheat allotetraploid. Genetics. 2002;160(4):1651-9.

12. Ozkan H, Levy AA, Feldman M. Allopolyploidy-induced rapid genome evolution in the wheat (Aegilops-Triticum) group. Plant Cell. 2001;13(8):1735-47.

13. Peng J, Sun D, Nevo E. Domestication evolution, genetics and genomics in wheat. Mol Breed. 2011;28(3):281-301.

14. Mayer KFX, Rogers J, Doležel J, Pozniak CJ, Eversole K, Feuillet C, et al. A chromosome-based draft sequence of the hexaploid bread wheat (Triticum aestivum) genome. Science. 2014;345(6194):1251788.

15. Alptekin $B$, Budak $H$. Wheat miRNA ancestors: evident by transcriptome analysis of a, B, and D genome donors. Funct Integr Genomics. 2017;17(2): 171-87.

16. Bariah I, Keidarfriedman D, Kashkush K. Identification of large-scale genomic rearrangements during wheat evolution and the underlying mechanisms. bioRxiv. 2018;1:478933.

17. Tang Z, Li M, Chen L, Wang Y, Ren Z, Fu S. New types of wheat chromosomal structural variations in derivatives of wheat-rye hybrids. PLoS One. 2014;9(10):e110282.

18. Cai Z, Liu H, He Q, Pu M, Chen J, Lai J, et al. Differential genome evolution and speciation of Coix lacryma-jobi L. and Coix aquatica Roxb. Hybrid Guangxi revealed by repetitive sequence analysis and fine karyotyping. BMC Genomics. 2014;15(1):1025.

19. Biscotti MA, Olmo E, Heslop-Harrison JS. Repetitive DNA in eukaryotic genomes. Chromosom Res. 2015;23(3):415-20.

20. Bouilly K, Chaves R, Leitão A, Benabdelmouna A, Guedes-Pinto H. Chromosomal organization of simple sequence repeats in the Pacific oyster (Crassostrea gigas): (GGAT) 4 , (GT) 7 and (TA $)_{10}$ chromosome patterns. J Genet. 2008;87(2):119-25

21. Cuadrado A, Cardoso M, Jouve N. Increasing the physical markers of wheat chromosomes using SSRs as FISH probes. Genome. 2008;51(10):809-15.

22. Cuadrado A, Jouve N. The nonrandom distribution of long clusters of all possible classes of trinucleotide repeats in barley chromosomes. Chromosom Res. 2007;15(6):711-20.

23. Badaeva ED, Amosova AV, Goncharov NP, Macas J, Ruban AS, Grechishnikova IV, et al. A set of cytogenetic markers allows the precise identification of all A-genome chromosomes in diploid and polyploid wheat. Cytogenet Genome Res. 2015;146(1):71-9.

24. Gong Z, Wu Y, Kobližková A, Torres GA, Wang K, lovene M, et al. Repeatless and repeat-based centromeres in potato: implications for centromere evolution. Plant Cell. 2012;24(9):3559-74.

25. Cho S, Kang S, Kang T, Park CS, Kim C, Kang C. Cytogenetic diversity of korean hexaploid wheat (Triticum aestivum L.) with simple sequence repeats (SSRs) by fluorescence in situ hybridization. J Crop Sci Biotechnol. 2018; 21(5):491-7.

26. Feng Z, Zhang M, Liu X, Liang D, Liu X, Hao M, et al. FISH karyotype comparison between $A^{b}$ - and $A$-genome chromosomes using oligonucleotide probes. J Appl Genet. 2020;61:313-22.

27. Lang T, Li G, Wang H, Yu Z, Chen Q, Yang E, et al. Physical location of tandem repeats in the wheat genome and application for chromosome identification. Planta. 2019;249(3):663-75.

28. Danilova TV, Friebe B, Gill BS. Development of a wheat single gene FISH map for analyzing homoeologous relationship and chromosomal rearrangements within the Triticeae. Theor Appl Genet. 2014;127(3):715-30.

29. Megyeri M, Farkas A, Varga M, Kovács G, Molnár-láng M, Molnár I. Karyotypic analysis of Triticum monococcum using standard repetitive DNA probes and simple sequence repeats. Acta Agron Hung. 2012;60(2):87-95

30. Adonina IG, Goncharov NP, Badaeva ED, Sergeeva EM, Petrash NV, Salina EA (GAA) $n$ microsatellite as an indicator of the a genome reorganization during wheat evolution and domestication. Comp Cytogenet. 2015;9(4): 533-47.
31. Komuro S, Endo R, Shikata K, Kato A. Genomic and chromosomal distribution patterns of various repeated DNA sequences in wheat revealed by a fluorescence in situ hybridization procedure. Genome. 2013:56(3):131-7.

32. Benson G. Tandem repeats finder: a program to analyze DNA sequences. Nucleic Acids Res. 1999:27(2):573-80.

33. Zimin AV, Puiu D, Hall R, Kingan S, Clavijo BJ, Salzberg SL. The first nearcomplete assembly of the hexaploid bread wheat genome, Triticum aestivum. Gigascience. 2017;6(11):1-7.

34. Ling H, Zhao S, Liu D, Wang J, Sun H, Zhang C, et al. Draft genome of the wheat A-genome progenitor Triticum urartu. Nature. 2013;496(7443):87-90.

35. Ling $H$, Ma B, Shi X, Liu H, Dong L, Sun H, et al. Genome sequence of the progenitor of wheat a subgenome Triticum urartu. Nature. 2018; 557(7705):424-8.

36. Miki Y, Yoshida K, Mizuno N, Nasuda S, Sato K, Takumi S. Origin of wheat Bgenome chromosomes inferred from RNA sequencing analysis of leaf transcripts from section Sitopsis species of Aegilops. DNA Res. 2019;26(2): $171-82$.

37. Mcintyre CL, Pereira S, Moran LB, Appels R. New Secale cereale (rye) DNA derivatives for the detection of rye chromosome segments in wheat. Genome. 1990;33(5):635-40.

38. Jiang M, Xaio ZQ, Fu S, Tang Z. FISH karyotype of 85 common wheat cultivars/lines displayed by ND-FISH using oligonucleotide probes. Cereal Res Commun. 2017:45(4):549-63.

39. Mirzaghaderi G, Houben A, Badaeva ED. Molecular-cytogenetic analysis of Aegilops triuncialis and identification of its chromosomes in the background of wheat. Mol Cytogenet. 2014;7(1):91

40. Dvorak J, Wang L, Zhu T, Jorgensen CM, Luo M, Deal KR, et al. Reassessment of the evolution of wheat chromosomes 4A, 5A, and 7B. Theor Appl Genet. 2018;131(11):2451-62.

41. Gill BS, Kimber G. Giemsa C-banding and the evolution of wheat. Proc Natl Acad Sci U S A. 1974;71(10):4086-90.

42. Endo TR, Gill BS. Somatic karyotype, heterochromatin distribution, and nature of chromosome differentiation in common wheat, Triticum aestivum L. em Thell. Chromosoma. 1984;89(5):361-9.

43. Levinson G, Gutman GA. Slipped-strand mispairing: a major mechanism for DNA sequence evolution. Mol Biol Evol. 1987;4(3):203-21.

44. Su H, Liu Y, Liu C, Shi Q, Huang Y, Han F. Centromere satellite repeats have undergone rapid changes in polyploid wheat subgenomes. Plant Cell. 2019; 31(9):2035-51.

45. Ijdo JW, Wells RA, Baldini A, Reeders ST. Improved telomere detection using a telomere repeat probe $(T T A G G G)_{n}$ generated by PCR. Nucleic Acids Res. 1991;19(17):4780.

46. Nagaki K, Tsujimoto H, Isono K, Sasakuma T. Molecular characterization of a tandem repeat, Afa family, and its distribution among Triticeae. Genome. 1995:38(3):479-86

\section{Publisher's Note}

Springer Nature remains neutral with regard to jurisdictional claims in published maps and institutional affiliations.

Ready to submit your research? Choose BMC and benefit from:

- fast, convenient online submission

- thorough peer review by experienced researchers in your field

- rapid publication on acceptance

- support for research data, including large and complex data types

- gold Open Access which fosters wider collaboration and increased citations

- maximum visibility for your research: over $100 \mathrm{M}$ website views per year

At $\mathrm{BMC}$, research is always in progress.

Learn more biomedcentral.com/submissions 